\title{
Nonlinear response of dissolved organic carbon concentrations in boreal lakes to increasing temperatures
}

\author{
Gesa A. Weyhenmeyera,* and Jan Karlsson ${ }^{b}$ \\ a Department of Aquatic Sciences and Assessment, Swedish University of Agricultural Sciences (SLU), Uppsala, Sweden \\ b Climate Impacts Research Centre (CIRC), Department of Ecology and Environmental Science, Umeå University, Abisko, Sweden
}

\begin{abstract}
Recent increases in concentrations of dissolved organic carbon (DOC) in lakes and rivers over large regions have been related to both changes in the climate and in atmospheric deposition chemistry. Using a data set of 1041 boreal lakes along a $13^{\circ}$ latitudinal gradient, sampled in 1995, 2000, and 2005, and an additional data set of 90 lakes along a $1000-\mathrm{m}$ altitudinal gradient at $68^{\circ} \mathrm{N}$, we show that DOC concentrations increase in a nonlinear way along a latitudinal and altitudinal temperature gradient. The nonlinear relation of DOC to increasing temperatures was consistent over space and time. Out of 14 meteorological, catchment, morphometric, and atmospheric deposition variables tested, the variable best explaining this kind of nonlinear pattern was the number of days when air temperatures exceeded $0^{\circ} \mathrm{C}$, i.e., the duration of the main growing and runoff season $\left(D_{T>0}\right)$. Using $D_{T>0}$ as an input variable, we were able to predict the nonlinear temperature response of DOC concentrations, both spatially $\left(R^{2}=0.90, p<0.0001\right)$ and temporally $\left(R^{2}=0.90, p<0.0001\right)$. $D_{T>0}$ has an advantage over other variables because it includes the time factor, which is decisive for the duration that biogeochemical processes can take place. We suggest that DOC concentrations in lakes are influenced by climate change and that present temperature increases over Sweden result in an accelerated DOC increase toward warmer geographical regions.
\end{abstract}

In humic lakes, the pool of organic carbon is dominated by dissolved organic carbon (DOC) imported from terrestrial surroundings. Terrestrial DOC plays a key role in aquatic ecosystems because it affects lake productivity, community structure, and metabolic balances (Jones 1998; Jansson et al. 2000, 2007), the global carbon budget (Cole et al. 2007), the availability of dissolved nutrients and metals (Franco and Heath 1983), and the thermal structure (Fee et al. 1996) and optical properties of water bodies (Morris et al. 1995). Recently, an increase in DOC concentrations over large regions in the Northern Hemisphere over the last decades has been observed (Monteith et al. 2007). Temporal changes in DOC concentrations have been attributed to changes in runoff (Andersson et al. 1991; Schindler et al. 1997; Erlandsson et al. 2008), temperature (Freeman et al. 2001; Worrall et al. 2004; Evans et al. 2006), solar radiation (Hudson et al. 2003), soil moisture (Worrall et al. 2006), and atmospheric deposition chemistry (Freeman et al. 2004; Evans et al. 2006; Monteith et al. 2007). Also, changes in the timing of ice breakup and snowmelt resulting in changes in the spring flood have been suggested to have an effect on DOC changes over time (Hongve et al. 2004; Weyhenmeyer 2008). In general, Mulholland (2003) proposed that concentrations and fluxes of DOC are more strongly related to climate and topography than to internal properties.

Considering that the majority of the climate-related drivers for DOC concentrations in lakes, such as runoff and temperature, show large variations between seasons at northern latitudes, we were interested to see whether temporal and spatial differences in length of seasons might have an effect on DOC concentrations in lakes. We

\footnotetext{
*Corresponding author: Gesa.Weyhenmeyer@ma.slu.se
}

hypothesized that the length of the main growing season, when main runoff events also take place, is a significant predictor for DOC concentrations in lakes, both on a spatial and a temporal basis. To test the hypothesis, we used a data set of 1041 boreal lakes along a $13^{\circ}$ latitudinal gradient from three lake inventories in 1995, 2000, and 2005 and related them to climatic, morphometric, catchment, and deposition variables in space and time. In addition, we validated our results by analyzing an independent data set of DOC concentrations from 90 subarctic lakes along a $1000-\mathrm{m}$ altitudinal gradient at $68^{\circ} \mathrm{N}$.

\section{Methods}

We used water chemical data from the Swedish national lake inventory from 1041 boreal lakes (more than 90\% forest in the catchment area and less than $1 \%$ agriculture; lake area ranging between $0.02 \mathrm{~km}^{2}$ and $317 \mathrm{~km}^{2}$ with a median of $\left.0.28 \mathrm{~km}^{2}\right)$. The lakes were evenly distributed over Sweden (Fig. 1). Water samples were taken in each lake during the autumn period of 1995, 2000, and 2005 when water temperatures were around $4{ }^{\circ} \mathrm{C}$ and the water column was fully mixed. Sampling was carried out in the middle of each lake at a depth of $0.5 \mathrm{~m}$. The sampling and analyzing procedure was performed by one and the same certified laboratory. Variables considered in this study for correlation analyses were $\mathrm{pH}$, alkalinity (Alk), conductivity (Cond), calcium (Ca), magnesium $(\mathrm{Mg})$, sodium $(\mathrm{Na})$, potassium $(\mathrm{K})$, chloride $(\mathrm{Cl})$, sulfate $\left(\mathrm{SO}_{4}\right)$, ammoniumnitrogen $\left(\mathrm{NH}_{4}-\mathrm{N}\right)$, nitrate-nitrogen $\left(\mathrm{NO}_{3}-\mathrm{N}\right)$, total nitrogen (TN), total phosphorus (TP), absorbance at $420 \mathrm{~nm}$ of $0.45-\mu \mathrm{m}$-filtered water in a $5-\mathrm{cm}$ cuvette (Color), total organic carbon (TOC), and reactive silica $(\mathrm{Si})$. All analyses were done according to standard limnological methods. 


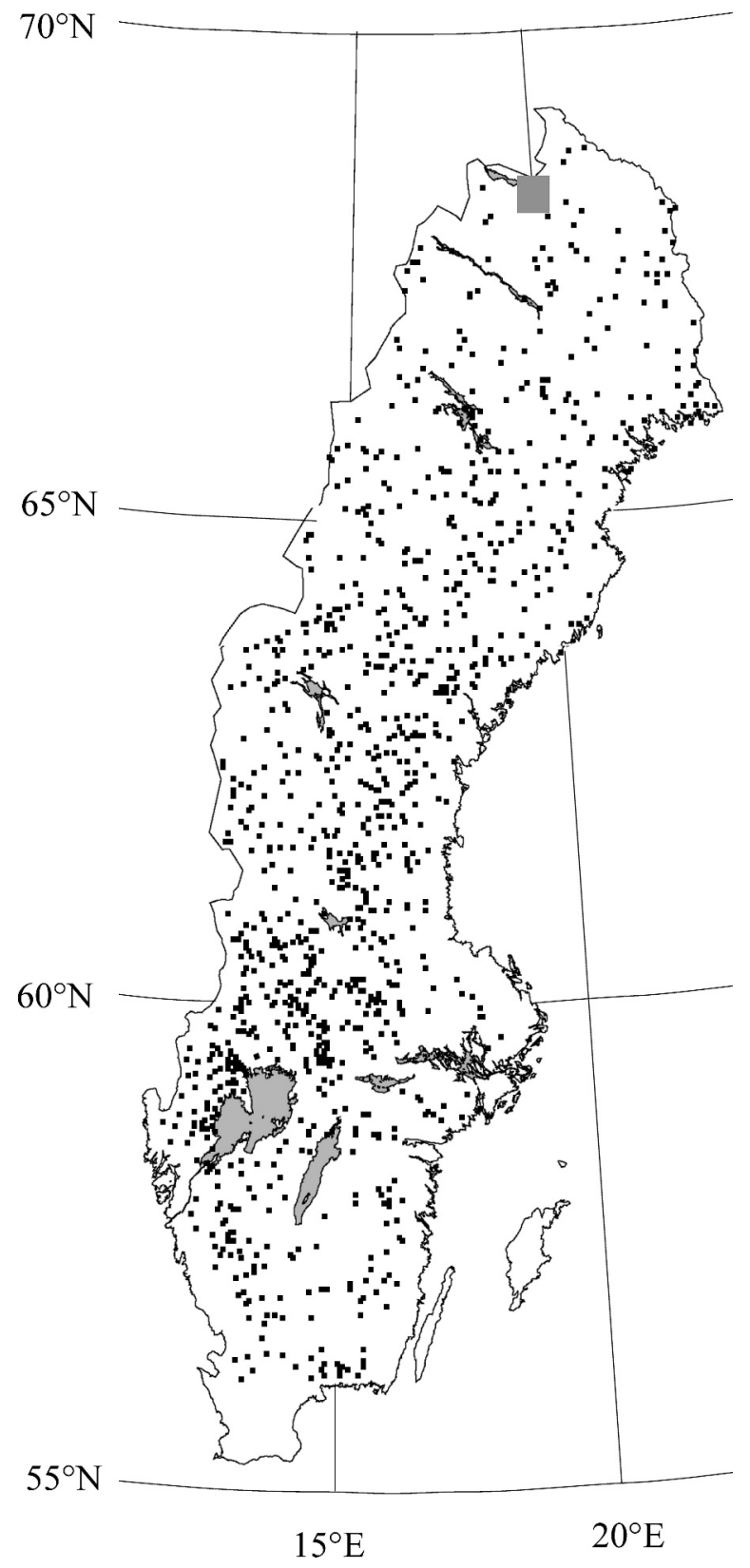

Fig. 1. Map of Sweden showing the locations of the 1041 boreal lakes (black dots). The gray square in the north shows the location from which DOC measurements from 90 lakes along an altitudinal gradient were available.

For further information on methods and for data from the national lake inventory, see http://www.ma.slu.se.

In addition to the large-scale data material, we used local-scale dissolved organic carbon (DOC) measurements that had been carried out in 90 subarctic lakes along a 1000-m altitudinal gradient (coniferous forest to alpine) at $68^{\circ} \mathrm{N}$ (Fig. 1). These data have been previously described in detail by Karlsson et al. (2001). Sampling was carried out in late summer-early autumn at $1-\mathrm{m}$ depth or as a composite sample (i.e., volume-weighted sample collected from several locations and depths across the lakes). DOC was analyzed following Karlsson et al. (2001). To compare the two data sets with TOC and DOC data, we converted TOC to DOC by multiplying TOC concentrations by 0.9 (Wetzel 2001). This method was recently used by Sobek et al. (2007) when they evaluated large-scale patterns and regulation of DOC. For Swedish boreal lakes, it is an appropriate approach since von Wachenfeldt and Tranvik (2008) measured both DOC and TOC concentrations in a variety of Swedish boreal lakes and found very good agreement, where DOC accounted for $97 \% \pm 5 \%$ of TOC.

Apart from the lake chemical data, we had available data on lake-specific catchment characteristics such as average annual runoff, air temperature, and precipitation (1961 to 1990), altitude of the catchment, area of the catchment, \% water, forest, sand, and above tree line in the catchment, and on lake morphometry, such as lake area and mean lake depth. Since our data material showed a substantial altitudinal gradient of up to a maximum of $1170 \mathrm{~m}$ above sea level, we needed to correct our coarse geographic information system (GIS)-derived temperature data (1961 to 1990) for altitude. According to Livingstone et al. (1999), we used an altitude correction for the GIS-derived temperature data of $-0.6^{\circ} \mathrm{C}$ per $100 \mathrm{~m}$, corresponding to the wet adiabatic lapse rate. With the altitude correction, we received 19 different temperature zones over which the lakes were distributed, ranging from $-11^{\circ} \mathrm{C}$ to $7^{\circ} \mathrm{C}$.

In addition to lake-specific air temperatures, we determined the lake-specific duration of the main growing and runoff season, i.e., the number of days when air temperatures exceed $0^{\circ} \mathrm{C}\left(D_{T>0}\right)$, according to the formula described in Weyhenmeyer et al. (2004):

$$
D_{T>0}=365 \mathrm{~d}-\left[(365 \mathrm{~d} / \Pi) \arccos \left(T_{\mathrm{m}} / T_{\mathrm{a}}\right)\right],
$$

where $T_{\mathrm{m}}$ corresponds to the annual mean air temperature, $T_{\mathrm{a}}$ is the annual air temperature amplitude, i.e., the maximum monthly mean air temperature minus the minimum monthly mean air temperature during a year, and d stands for days. To determine $D_{T>0}$, we had complete time series of monthly mean air temperatures from 72 sites distributed all over Sweden from 1961 to 2005 available. Since 72 meteorological sites were too few to represent our lake data, we took advantage of the fact that we observed a strong relation between annual mean air temperatures and the annual air temperature amplitudes during 1961 to $2005\left(R^{2}=0.50, p<0.0001, n=3168\right)$ and determined lake-specific, altitude-corrected $D_{T>0}$ values by the equation:

$$
\begin{aligned}
D_{T>0}= & 365 \mathrm{~d}-\{(365 \mathrm{~d} / \Pi) \arccos \\
& {\left.\left[T_{\mathrm{m}} /\left(-1.26 T_{\mathrm{m}}+28.21\right)\right]\right\}, }
\end{aligned}
$$

where $T_{\mathrm{m}}$ corresponds to the lake-specific air temperature data derived after the altitude correction. The results of the simplified Eq. 2 corresponded well to the results of Eq. 1 (Fig. 2).

In addition to complete time series of monthly mean air temperatures, we had complete time series of monthly sum precipitation from 277 sites distributed all over Sweden from 1961 to 2005 available. All statistical analyses were performed in JMP, version 7.0.1. (SAS Institute 2007). 


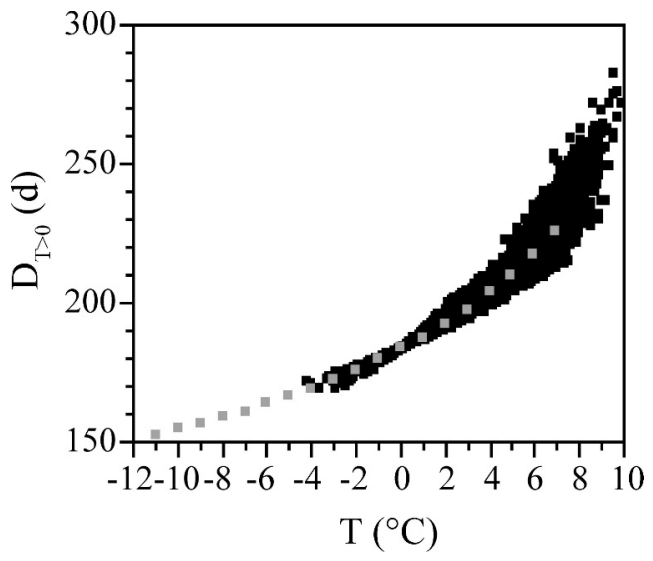

Fig. 2. Relation between measured annual mean air temperatures and the duration of the main growing and runoff season $\left(D_{T>0}\right.$, see Eq. 1) for 72 meteorological sites during each year from 1961 to 2005 (black dots). Also shown are calculated $D_{T>0}$ values using Eq. 2 (gray dots).

\section{Results}

By relating all 15 available water chemical variables to total organic carbon (TOC) concentrations in our 3123 water samples, taken from three lake inventories of 1041 Swedish lakes, we found that TOC was best related to absorbance of filtered water $\left(R^{2}=0.81, p<0.0001, n=\right.$ 3123 ) and second best to total nitrogen (TN) concentrations $\left(R^{2}=0.17, p<0.0001, n=3123\right)$. We used TN concentrations to account for atmospheric deposition variations along a latitudinal gradient, since nitrogen concentrations in Swedish lakes best reflect the pattern of atmospheric wet deposition (Weyhenmeyer et al. 2007). Sulfate concentrations, which can also be used as a proxy for atmospheric deposition, explained only $1 \%$ of the variations in TOC concentrations $\left(R^{2}=0.01, p<0.0001, n\right.$ $=3123$ ).

On a spatial basis, TOC concentrations in our boreal lakes were related to latitude and altitude $(p<0.0001)$. The relation had an exponential character rather than a simple linear one, in particular, at the highest latitudes and altitudes (Fig. 3a,b). The exponential character became more pronounced when we replaced altitude and latitude by lake-specific annual mean air temperatures (Fig. 3c).

A TOC dependency on latitude and altitude was expected since all tested climatic (average annual runoff, air temperature, duration of main growing and runoff season, and precipitation of the catchment), morphometric (mean lake depth, lake area), catchment (catchment area, four different land-use variables), and deposition (TN concentrations) variables were significantly related to latitude $(p<0.05)$ and altitude $(p<0.05)$. When we took the available climatic, morphometric, catchment, and deposition variables and used them as input variables for a standard least squares model to explain TOC concentrations in Swedish lakes, we found good model performance $\left(R^{2}=0.65, p<0.0001, n=3123\right)$, where all input variables except for the catchment size made a significant contribution to the model $(p<0.05)$. From the input variables,
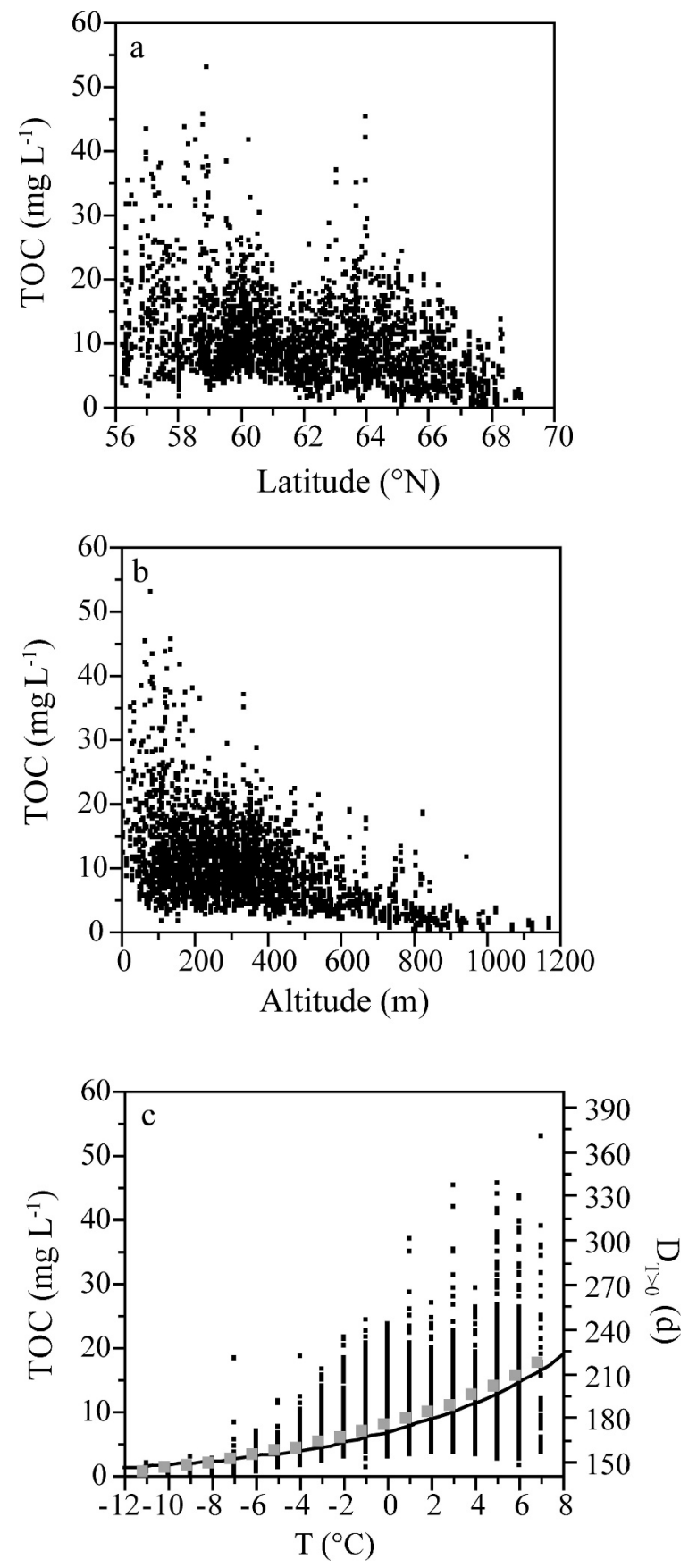

Fig. 3. Total organic carbon (TOC) concentrations of 3123 lake water samples along (a) a latitudinal gradient, (b) an altitudinal gradient, and (c) lake-specific annual mean air temperatures (T). TOC concentrations increase in a nonlinear way with increasing temperatures, clarified by mean values per degree temperature (gray dots). The nonlinear increase corresponds to the nonlinear increase in the duration of the main growing and runoff season $\left(D_{T>0}\right.$; black line for which values were taken from Fig. 2).

lake-specific annual mean air temperatures and lakespecific $D_{T>0}$ values turned out to give the most significant results in explaining TOC concentrations in Swedish lakes (nonparametric Spearman's $\rho$ test, $R=0.49, p<0.0001, n$ $=3123$; Table 1). Lake-specific annual mean air temper- 
Table 1. Nonparametric Spearman's $\rho$ test for relations to dissolved organic carbon concentrations in 1041 boreal lakes (for determination of DOC and for abbreviations, see Methods). For DOC and total nitrogen, 3123 different measurements from 1041 lakes from three lake inventories were available; for climatic, morphometric, and catchment variables, only 1041 different data points were accessible, i.e., lake-specific average values from 1961 to 1990 (see Methods).

\begin{tabular}{lrc}
\hline \hline \multicolumn{1}{c}{ Variable } & $R$ value & Significance level \\
\hline Lake-specific $D_{T>0}$ & 0.49 & $<0.0001$ \\
Lake-specific air temperature & 0.49 & $<0.0001$ \\
\% above tree line & -0.48 & $<0.0001$ \\
Total nitrogen & 0.40 & $<0.0001$ \\
Mean lake depth & -0.40 & $<0.0001$ \\
Lake-specific runoff & -0.35 & $<0.0001$ \\
$\%$ forest & 0.33 & $<0.0001$ \\
$\%$ water & -0.30 & $<0.0001$ \\
Lake area & -0.30 & $<0.0001$ \\
Catchment area & -0.17 & $<0.0001$ \\
\% sand & 0.13 & $<0.0001$ \\
Lake-specific precipitation & -0.13 & $<0.0001$ \\
\hline
\end{tabular}

atures and $D_{T>0}$ are by definition linked to each other in a nonlinear way (Eq. 1; Fig. 2). We found that TOC concentrations showed the same kind of nonlinear relation to temperature as did $D_{T>0}$ (Fig. 3c). As a consequence, there was a highly significant simple linear relationship between $D_{T>0}$ and TOC $(p<0.0001)$. Among the climatic, catchment, and morphometric variables, $D_{T>0}$ turned out to be the most powerful explanatory variable and was simply linearly related to TOC concentrations in Swedish lakes. By converting TOC concentrations to DOC concentrations by multiplying TOC by 0.9 (see Methods), our large-scale results corresponded well to an independent data set of local-scale DOC concentrations available from 90 lakes along an altitudinal temperature gradient at $68^{\circ} \mathrm{N}$ (Fig. 1), although the slope of the relation between $D_{T>0}$ and DOC concentrations was slightly steeper on a localscale compared to large-scale (Fig. 4a,b). Since the simple conversion from TOC to DOC seemed to provide reasonable results for our Swedish lakes, we used the converted TOC concentrations for further analyses, and we tested whether the results gained from the spatial analysis were transferable to temporal patterns. Based on the results from the spatial basis, we predicted a nonlinear increase in DOC concentrations with increasing temperatures (Fig. 5). Taking the mean values of DOC and air temperature for three different climatic regions during each of the three years of lake inventories in 1995, 2000, and 2005, we observed the same kind of accelerated DOC concentrations with increasing temperatures (Fig. 5). Relating the predicted DOC concentrations to the measured DOC concentrations revealed a highly significant relationship $\left(R^{2}=0.90, p\right.$ $<0.0001, n=9$ ). The best prediction was gained for the coldest geographical region with a slope of 1 and an intercept of $-1\left(R^{2}=0.98, p<0.05, n=3\right)$. DOC concentrations in the two other geographical regions were slightly overestimated for the warmest geographical region at southern latitudes of Sweden and slightly underestimated for middle latitudes. The temporal development nicely



Fig. 4. Relationship between dissolved organic carbon (DOC) lake concentrations and the lake-specific duration of the main growing and runoff season $\left(D_{T>0}\right)$ on a (a) large and (b) local scale. The black squares and black regression line in (a) represent mean values of each degree temperature from Fig. $3 \mathrm{c}$ $\left(\mathrm{DOC}=0.20 D_{T>0}-29 ; R^{2}=0.90, p<0.0001, n=19\right)$. The gray squares and the gray regression line in (b) represent data from 90 lakes in the gray square of Fig. 1. The small gray squares correspond to all local-scale measurements, the bigger ones correspond to mean values upon which the regression is based on $\left(\mathrm{DOC}=0.24 D_{T>0}-37 ; R^{2}=0.87, p<0.01, n=7\right)$.

followed, however, the predicted development, showing the faster DOC response to increasing temperatures in the warmest geographical region (Fig. 5). Tests of all other variables that showed temporal variations during the $10-\mathrm{yr}$ investigation period, i.e., climatic and 15 water chemical variables, showed that temperature, $D_{T>0}$, and color were best at explaining DOC variations over space and time (Table 2). No relation could be established between DOC concentrations and precipitation, total nitrogen, and sulfate concentration patterns over Sweden (Table 2).

\section{Discussion}

Several studies are available where DOC concentrations across lakes in the Northern Hemisphere were explained by climatic, catchment, and morphometric variables (e.g., Engstrom 1987; Rasmussen et al. 1989; Aitkenhead and McDowell 2000). On a global scale, previous studies had shown that altitude was one of the most important variables in explaining DOC lake concentrations (Xenopoulos et al. 2003; Sobek et al. 2007). The results from the global scale correspond to the results of this study, where altitude also came out as a significant factor explaining DOC concentrations in Swedish lakes. Altitude is a proxy 


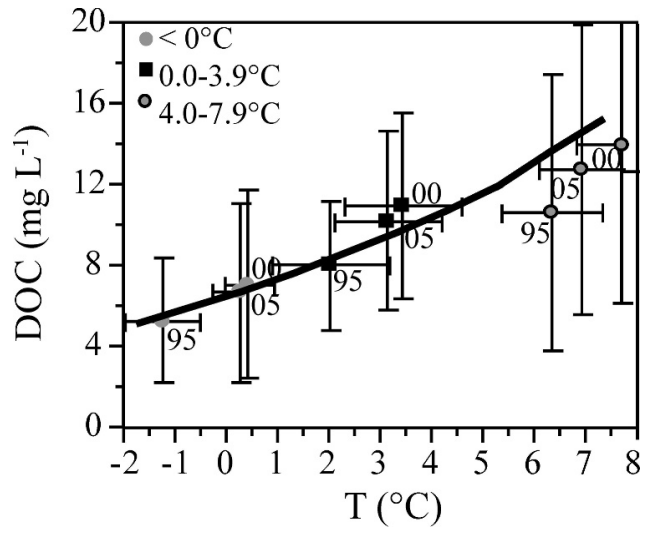

Fig. 5. Relationship between dissolved organic carbon (DOC) lake concentrations and annual mean air temperatures on a temporal basis for three different regions: a region where annual mean air temperatures normal values (1961-1990) remain below $0^{\circ} \mathrm{C}$, a region where annual mean air temperatures normal values remain between $0^{\circ} \mathrm{C}$ and $3.9^{\circ} \mathrm{C}$, and a region where annual mean air temperatures normal values remain between $4.0^{\circ} \mathrm{C}$ and $7.9^{\circ} \mathrm{C}$. Shown are regional mean values and standard deviations during 1995, 2000, and 2005. Also shown are predicted DOC concentrations (black line) where we used the results from the spatial analysis, i.e., the regression equation of Fig. $4 \mathrm{a}$ : $\mathrm{DOC}=0.20 D_{T>0}-29$, which we then plotted along a temperature gradient.

for a variety of variables, such as runoff, air temperatures, and catchment slope, that are known to affect the terrestrial DOC production and the export to lakes and thus in-lake DOC concentrations (Sobek et al. 2007). Altitude has, however, the disadvantage that it is an unsatisfying variable when changes over time need to be examined. As outlined in the introduction, changes over time have so far been attributed to changes in runoff, temperature, solar radiation, soil moisture, atmospheric deposition chemistry, and the timing of ice breakup and snowmelt. The question arises how the results obtained from spatial studies can best be combined with the ones gained from temporal studies. Assuming that land use, catchment slope, and lake morphometry are not changing considerably over a relatively short time span, e.g., $10 \mathrm{yr}$, altitude at a specific latitude can be considered as a proxy for annual mean air temperatures (Ahrens 2005). Indeed, we found that annual mean air temperatures were related to DOC concentrations in lakes, but this relationship was exponential rather than linear (Fig. 3c). It is very common for exponential or logarithmic patterns to result when variables are plotted against latitude and altitude because they are proxies for air temperature (Valentini et al. 2000; Xenopoulos et al. 2003; Sobek et al. 2007; this study). These exponential or logarithmic patterns might turn into simple linear relationships when latitude and altitude are replaced by $D_{T>0}$ as shown in this study (Fig. 4). We found no other variable that was able to reveal a similar significant simple linear relationship to DOC concentrations, not even total nitrogen concentrations from the same water samples, and looking at the global DOC results of Xenopoulos et al. (2003) and Sobek et al. (2007), no variable was related to DOC concentrations in a simple linear way. $D_{T>0}$ is a measure of both annual mean air
Table 2. Nonparametric Spearman's $\rho$ test for relations to temporal variations of dissolved organic carbon concentrations (for determination of DOC and for abbreviations, see Methods). For each correlation, mean values of three years, i.e., 1995, 2000, and 2005 for three different regions were used, i.e., a region where annual mean air temperatures normal values (1961-1990) remain below $0^{\circ} \mathrm{C}$, a region where annual mean air temperatures normal values remain between $0^{\circ} \mathrm{C}$ and $3.9^{\circ} \mathrm{C}$, and a region where annual mean air temperatures normal values remain between $4.0^{\circ} \mathrm{C}$ and $7.9^{\circ} \mathrm{C}$. This approach gave nine data points for each correlation. For air temperature, $D_{T>0}$, and precipitation, available long-term data series were used (see Methods). The most significant relation is shown in Fig. 5.

\begin{tabular}{lcc}
\hline \hline \multicolumn{1}{c}{ Variable } & $R$ value & Significance level \\
\hline$D_{T>0}$ & 0.98 & $<0.0001$ \\
Air temperature & 0.98 & $<0.0001$ \\
Color & 0.97 & $<0.0001$ \\
$\mathrm{NH}_{4}-\mathrm{N}$ & 0.80 & 0.010 \\
$\mathrm{pH}$ & -0.78 & 0.013 \\
$\mathrm{NO}_{3}-\mathrm{N}$ & 0.77 & 0.016 \\
$\mathrm{Ca}$ & 0.75 & 0.020 \\
$\mathrm{Conductivity}$ & 0.70 & 0.036 \\
$\mathrm{Na}$ & 0.68 & 0.042 \\
$\mathrm{~K}$ & 0.65 & 0.058 \\
$\mathrm{Cl}$ & 0.65 & 0.058 \\
$\mathrm{Si}$ & 0.63 & 0.067 \\
$\mathrm{Mg}$ & 0.62 & 0.077 \\
$\mathrm{SO}$ & 0.47 & 0.205 \\
$\mathrm{TN}$ & 0.37 & 0.332 \\
$\mathrm{Alk}$ & 0.17 & 0.668 \\
$\mathrm{TP}$ & 0.13 & 0.732 \\
$\mathrm{Precipitation}$ & 0.13 & 0.732 \\
\hline
\end{tabular}

temperatures and the annual air temperature amplitude. $D_{T>0}$ not only integrates temperature but also timing events, e.g., the timing of ice on and off, snowmelt, spring flood, main biological activity, which are all known to strongly influence DOC concentrations in lakes. In addition, $D_{T>0}$ reflects continentality, which affects both precipitation and atmospheric deposition patterns. Since we found highly significant relationships between $D_{T>0}$ and DOC concentrations on local and large scales (Fig. 4) that could be used to predict DOC concentrations on a temporal scale (Fig. 5) and since no other variable was equally well related to DOC concentrations (Table 2), we suggest that $D_{T>0}$ is a very suitable variable to explain variations in DOC concentrations over space and time.

Our local-scale DOC concentrations showed a slightly stronger increase with increasing $D_{T>0}$ values than the large-scale DOC concentrations did (Fig. 4). We believe that catchment slope might have an additional effect on the local-scale DOC concentrations since these concentrations were all gained from lakes of Sweden's steepest mountainous area, where the thickness of organic soil horizons and the degree of waterlogged soils usually decreases. We also found slightly deviating results between spatial and temporal DOC data for lakes located at middle and southern latitudes of Sweden. Many explanations are possible for this phenomenon, one of which is that our lakes are not evenly distributed over all temperature regions, giving a bias when mean values on a spatial and 
temporal scale are used. Another explanation for deviating patterns might be the increasing variability in DOC concentrations with increasing temperatures (Fig. 3c). On a spatial basis, the increasing variability might partly be explained by more heterogeneous catchment areas toward more densely populated southern geographical regions of Sweden. However, since we also get an increasing variability in DOC concentrations with increasing temperatures on a temporal basis (Fig. 5), parts of the variability increase might be attributed to the fact that even $D_{T>0}$ increases its variability with increasing temperatures (Fig. 2). Capture of this high variability with a simple modeling approach as used in this study is unrealistic, which explains why we received best model results for regions with a low variability in DOC concentrations, i.e., regions where annual mean air temperatures remain below $0^{\circ} \mathrm{C}$. However, taking regional mean values, we consider our DOC prediction with $D_{T>0}$ values to be acceptable for warmer geographical regions, both on a spatial and a temporal scale (Figs. 4, 5).

$D_{T>0}$ is a nonlinear function of air temperature, since it is described as an arccosine function of air temperature. If air temperature further increases, as is most likely on a global scale (IPCC 2007), it is probable that we will receive accelerated changes of DOC toward warmer geographical regions, provided that no other changes affecting DOC concentrations will occur. Such accelerated changes toward warmer geographical regions have already been observed for Sweden (Weyhenmeyer 2008) and could be confirmed in this study (Fig. 5). In a closer look at Monteith's et al. (2007) global DOC data set, there is also a tendency for significant DOC trends to be found in warmer geographical regions. For Sweden, it is predicted that especially winters will become warmer (Kjellström 2004). Warmer winters will result in a shortening of the period with snow and ice cover. The importance of wintertime climatic control on DOC dynamics in lakes has already been identified by Belzile et al. (2002), Park et al. (2005), Karlsson et al. (2008), and Weyhenmeyer (2008). From these studies, DOC concentrations are expected to increase along with warmer winters.

We conclude that $D_{T>0}$ is a suitable measure for DOC concentrations in lakes, showing that DOC is influenced by climate change. $D_{T>0}$ includes seasonality, which is a factor for biogeochemical processes that influence DOC concentrations. DOC predictions using $D_{T>0}$ worked well when we used regional mean values, both on a spatial and a temporal scale $\left(R^{2}=0.90, p<0.0001\right)$. Taking each lake individually, however, a variety of additional variables need to be considered for a precise prediction of DOC concentrations, as the roughly estimated variable $D_{T>0}$ could only explain $24 \%$ of the DOC variation. More research is needed to combine results from individual lake studies with the ones from regional lake studies.

\section{Acknowledgments}

Funding for this study was provided by the Royal Swedish Academy of Sciences (Knut and Alice Wallenberg Foundation) and the Swedish Research Council. Many thanks go to the Swedish Environmental Protection Agency and the Department of Aquatic Sciences and Assessment for financing, sampling, and analyzing thousands of water samples. We also thank two anonymous reviewers for their constructive comments. The time series of the air temperature data were kindly provided by the Swedish Meteorological and Hydrological Institute.

\section{References}

Ahrens, C. D. 2005. Essentials of meteorology. Thomson Brooks/ Cole.

Aitkenhead, J. A., And W. H. McDowell. 2000. Soil C: N ratios as predictor of annual riverine DOC flux at local and global scales. Glob. Biogeochem. Cy. 14: 127-138.

Andersson, T., Å. Nilsson, and M. Jansson. 1991. Coloured substances in Swedish lakes and rivers-temporal variation and regulating factors. Lect. Notes Earth Sci. 33: 243-253.

Belzile, C., J. A. E. Gibson, and W. F. Vincent. 2002. Colored dissolved organic matter and dissolved organic carbon exclusion from lake ice: Implications for irradiance transmission and carbon cycling. Limnol. Oceanogr. 47: 1283-1293.

Cole, J. J., Y. T. Prairie, N. F. Caraco, W. H. McDowell, L. J. Tranvik, R. G. Striegl, C. M. Duarte, P. Kortelainen, J. A. Downing, J. J. Middelburg, and J. Melack. 2007. Plumbing the global carbon cycle: Integrating inland waters into the terrestrial carbon budget. Ecosystems 10: 171-184.

EngSTROM, D. R. 1987. Influence of vegetation and hydrology on the humus budgets of Labrador lakes. Can. J. Fish. Aquat. Sci. 44: 1306-1314.

Erlandsson, M., I. Buffam, J. Fölster, H. Laudon, J. Temnerud, G. A. Weyhenmeyer, and K. Bishop. 2008. Thirty-five years of synchrony in the organic matter concentrations of Swedish rivers explained by variation in flow and sulphate. Glob. Change Biol. 14: 1-8.

Evans, C. D., P. J. Chapman, J. M. Clark, D. T. Monteith, and M. S. Cresser. 2006. Alternative explanations for rising dissolved organic carbon export from organic soils. Glob. Change Biol. 12: 2044-2053.

Fee, E. J., R. E. Hecky, S. E. M. Kasian, and D. R. Cruikshank. 1996. Effects of lake size, water clarity, and climatic variability on mixing depths in Canadian Shield lakes. Limnol. Oceanogr. 41: 912-920.

Franco, D. A., and R. T. Heath. 1983. Abiotic uptake and photodependent release of phosphate from high-molecularweight humic-iron complexes in bog lakes, p. 467-480. In R. F. Christman and E. Gjessing [eds.], Aquatic and terrestrial humic materials. Ann Arbor Scientific Publications.

Freeman, C., C. D. Evans, D. T. Monteith, B. Reynolds, and N. FENNER. 2001. Export of organic carbon from peat soils. Nature 412: 785.

, N. Fenner, N. J. Ostle, H. Kang, D. J. Dowrick, B. Reynolds, M. A. Lock, D. Sleep, S. Hughes, And J. Hudson. 2004. Export of organic carbon from peatlands under elevated carbon dioxide levels. Nature 430: 195-198.

Hongve, D., G. Riise, and J. F. Kristiansen. 2004. Increased colour and organic acid concentrations in Norwegian forest lakes and drinking water-a result of increased precipitation? Aquat. Sci. 66: 231-238.

Hudson, J. J., P. J. Dillon, And K. M. Somers. 2003. Long-term patterns in dissolved organic carbon in boreal lakes: The role of incident radiation, precipitation, air temperature, southern oscillation and acid deposition. Hydrol. Earth Sys. Sci. 7: 390-398.

IPCC (Intergovernmental Panel on Climate Change). 2007. Summary for policymakers, p. 1-18. In S. Solomon, D. Qin, M. Manning, Z. Chen, M. Marquis, K. B. Averyt, M. Tignor, and H. L. Miller [eds.], Climate change 2007: The physical 
science basis. Contribution of Working Group 1 to the Fourth Assessment Report of the Intergovernmental Panel on Climate Change. Cambridge Univ. Press.

Jansson, M., A.-K. Bergström, P. Blomgvist, and S. Drakare. 2000. Allochthonous organic carbon and phytoplankton/ bacterioplankton production relationships in lakes. Ecology 81: $3250-3255$.

-, L. Persson, A. M. Deroos, R. I. Jones, and L. J. Tranvik. 2007. Terrestrial carbon and intraspecific sizevariation shape lake ecosystems. Trends Ecol. Evol. 22: $316-322$.

Jones, R. I. 1998. Phytoplankton, primary production and nutrient cycling, p. 145-195. In D. O. Hessen and L. J. Tranvik [eds.], Aquatic humic substances: Ecology and biogeochemistry. Springer-Verlag.

KARlsson, J., J. AsK, AND M. JANSSON. 2008. Winter respiration of allochthonous and autochthonous organic carbon in a subarctic clear-water lake. Limnol. Oceanogr. 53: 948-954.

$\longrightarrow$, A. Jonsson, AND M. JANSSON. 2001. Bacterioplankton production in lakes along an altitude gradient in the subarctic north of Sweden. Microb. Ecol. 42: 372-382.

KJellström, E. 2004. Recent and future signatures of climate change in Europe. Ambio 33: 193-198.

Livingstone, D. M., A. F. Lotter, and I. R. Walker. 1999. The decrease in summer surface temperature with altitude in Swiss Alpine lakes: A comparison with air temperature lapse rate. Arctic, Antarct. Alp. Res. 31: 341-352.

Monteith, D., J. L. Stoddard, J. L. C. D. Evans, H. A. de Wit, M. Forsius, T. Hogasen, A. Wilander, B. L. Skjelkvale, D. S. Jeffries, J. VuorenmaA, B. Keller, J. Kopacek, and J. VESELY. 2007. Dissolved organic carbon trends resulting from changes in atmospheric deposition chemistry. Nature 450: 537-540.

Morris, D. P., H. Zagarese, C. E. Williamson, E. G. Balseiro, B. R. Hargreaves, B. Modenutti, R. Moeller, and C. QueImalinos. 1995. The attenuation of solar UV radiation in lakes and the role of dissolved organic carbon. Limnol. Oceanogr. 40: 1381-1391.

Mulholland, P. J. 2003. Large-scale patterns in dissolved organic concentration, flux, and sources, p. 139-160. In S. Findlay and R. L. Sinsabaugh [eds.], Aquatic ecosystems - interactivity of dissolved organic matter. Academic Press.

Park, J. I.-H., M. J. Mitchell, And C. T. Driscoll. 2005. Wintertime climatic control on dissolved organic carbon export and surface water chemistry in an Adirondack forested watershed. Environ. Sci. Technol. 39: 6993-6998.

Rasmussen, J. B., L. Godbout, and M. Schallenberg. 1989. The humic content of lake water and its relationship to watershed and lake morphometry. Limnol. Oceanogr. 34: $1336-1343$.
SAS Institute. 2007. JMP statistics and graphics guide, Version 7.0.1 [Internet]. SAS Institute, Cary, North Carolina. Available from http://www.jmp.com. Accessed 1 July 2008.

Schindler, D. W., P. J. Curtis, S. E. Bayley, B. R. Parker, K. G. Beaty, and M. P. Stainton. 1997. Climate-induced changes in the dissolved organic carbon budgets of boreal lakes. Biogeochemistry 36: 9-28.

Sobek, S., L. J. Tranvik, Y. T. Prairie, P. Kortelainen, and J. J. Cole. 2007. Patterns and regulation of dissolved organic carbon: An analysis of 7,500 widely distributed lakes. Limnol. Oceanogr. 52: 1208-1219.

VAlentini, R., AND others. 2000. Respiration as the main determinant of carbon balance in European forests. Nature 404: $861-864$.

von Wachenfeldt, E., AND L. J. TRANVIK. 2008. Sedimentation in boreal lakes - the role of flocculation of allochthonous dissolved organic matter in the water column. Ecosystems 11: $803-814$.

Wetzel, R. G. 2001. Limnology. Lake and river ecosystems, $3^{\text {rd }}$ ed. Academic Press.

Weyhenmeyer, G. A. 2008. Water chemical changes along a latitudinal gradient in relation to climate and atmospheric deposition. Climatic Change 88: 199-208.

- E. Jeppesen, R. Adrian, L. Arvola, T. Jankowski, E. Jennings, P. Noges, T. Noges, And D. Straile. 2007. Nitratedepleted conditions on the increase in shallow northern European lakes. Limnol. Oceanogr. 52: 1346-1353.

, M. Meili, AND D. M. Livingstone. 2004. Nonlinear temperature response of lake ice breakup. Geophys. Res. Let. 31: L07203, doi:10.1029/2004GL019530.

Worrall, F., T. P. Burt, and J. K. Adamson. 2006. Trends in drought frequency - the fate of DOC export from British peatlands. Climatic Change 76: 339-359.

$\longrightarrow$, R. Harriman, C. D. Evans, C. D. Watts, J. Adamson, C. Neal, E. Tipping, T. Burt, I. Grieve, D. Monteith, P. S. Naden, T. Nisbet, B. Reynolds, and P. Stevens. 2004. Trends in dissolved organic carbon in UK rivers and lakes. Biogeochemistry 70: 369-402.

Xenopoulos, M. A., D. M. Lodge, J. Frentress, T. A. Kreps, S. D. Bridgham, E. Grossman, and C. J. Jackson. 2003. Regional comparisons of watershed determinants of dissolved organic carbon in temperature lakes from the Upper Great Lakes region and selected regions globally. Limnol. Oceanogr. 48: 2321-2334.

Associate Editors: Warwick F. Vincent and John P. Smol

Received: 05 September 2008 Accepted: 19 February 2009 Amended: 05 March 2009 